\title{
Apoptosis induction and inhibition of cellular proliferation by angiotensin II: possible implication and perspectives
}

\author{
B. Antus ${ }^{1,2}$, I. Mucsi ${ }^{1,3}$, L. Rosivall ${ }^{1}$ \\ ${ }^{1}$ Department of Pathophysiology, International Training and Research Center in Nephrology, \\ Faculty of Medicine, Semmelweis University, Budapest, Hungary \\ 2 Department of Nephrology, University Hospital Essen, Germany \\ ${ }^{3} 1$ st Department of Internal Medicine, Faculty of Medicine, Semmelweis University, Budapest, Hungary

\section{Received: December 10, 1999} \\ Accepted: February 24, 2000 \begin{abstract}
metabolism and blood pressure. Molecular cloning and pharmacological studies have defined two major classes of Angiotensin II (Ang II) receptors, designated $\mathrm{AT}_{1}$ and $\mathrm{AT}_{2}$. Recently, it has been well recognized that Ang II, beside its classical physiological actions, is a profibrogenic peptide and displays characteristics of a growth factor. The emerging picture suggests that angiotensin receptor subtypes exert opposing features in many aspects of their biological function, most importantly in cellular growth and proliferation. Accordingly, the proliferative and/or growth-promoting effects of Ang II are thought to be mediated by $\mathrm{AT}_{1}$ receptor, whereas the $\mathrm{AT}_{2}$ receptor subtype may have growth-inhibitory properties. The novel finding that Ang II is able to induce apoptosis by $\mathrm{AT}_{2}$ receptors in diverse cell types is of great scientific interest, as recent studies revealed a role for apoptosis as a deliberate form of cell death in the pathogenesis of various cardiovascular diseases such as heart failure and vascular remodeling. Furthermore apoptotic cell death might occur during the development of progressive glomerulosclerosis. It is tempting to speculate that autocrine-paracrine vasoactive substances such as Ang II might regulate these apoptotic processes during pathogenic conditions.
\end{abstract} \\ The renin-angiotensin system plays a pivotal role in the regulation of fluid, electrolyte
}

Keywords: Angiotensin II, $\mathrm{AT}_{1}$ and $\mathrm{AT}_{2}$ receptors, proliferation, apoptosis, heart failure, glomerulosclerosis

Correspondence should be addressed to

László Rosivall MD, PhD, DSc Med

Nephrology Research and Trainig Centrum

Department of Pathophysiology

Faculty of Medicine, Semmelweis University H-1089 Budapest, Nagyvárad tér 4, Hungary

Phone/Fax: +36 $12100-100$

Email: rosivall@net.sote.hu 
It has been well known for more than 40 years that Ang II, the dominant effector of the renin-angiotensin system (RAS), regulates numerous physiological responses including salt and water balance, aldosteron release and blood pressure. The RAS has traditionally been considered as an endocrine system in that only the renin, the enzyme responsible for prohormone-to-hormone conversion was believed to be secreted from the kidney into the blood while the effector peptide Ang II was produced extrarenally and transported by the blood to its target organs such as the adrenal cortex and the arterial smooth muscle. Later this concept has been revised for several reasons. Firstly, it became evident that all components of the RAS are produced within the kidney and also a number of extrarenal tissues. Tissular expression of the RAS has been attributed physiological function both in cardiovascular as well as in renal systems. For example, micropuncture studies clearly demonstrated that the intrarenal RAS as a local regulatory mechanism has a major impact on renal hemodynamics [reviewed in 1, 2]. Secondly, in the last decade it has been generally appreciated that Ang II, besides its vasoactive actions, is a profibrogenic peptide and displays characteristics of a growth factor. In favour of this concept, Ang II has been shown to stimulate the production of extracellular matrix (ECM) proteins and to induce cellular hypertrophy and/or proliferation in various cell types including vascular smooth muscle cells, cardiac myocytes, glomerular mesangial cells and tubular epithelial cells [reviewed in 3-5].

Using nonpeptide agonists and antagonists, two major classes of Ang II receptors have been described, which are commonly referred to as the angiotensin receptor type I $\left(\mathrm{AT}_{1}\right)$ and type II $\left(\mathrm{AT}_{2}\right)$ [6-9]. Both of them have been cloned and appeared to be members of the seven transmembrane domain receptor family. However, $\mathrm{AT}_{1}$ and $\mathrm{AT}_{2}$ receptors share only $30 \%$ sequence homology and have distinct functional and pharmacological properties.

The molecular cloning of angiotensin receptor subtypes led to the possibility to distinguish different receptor-mediated actions of Ang II, which appeared to be opponing in many aspects, for example, in the regulation of vascular tone, ECM metabolism or (probably more importantly) in the control cellular proliferation and growth. Accordingly, recent studies provided evidence that the profibrogenic, proliferative and/or growth-promoting effects of Ang II are mediated by the $\mathrm{AT}_{1}$ receptor subtype, whereas the $\mathrm{AT}_{2}$ receptor may have antiproliferative properties. In addition, activation of the $\mathrm{AT}_{2}$ receptor subtype might direct cells into apoptosis (programmed cell death) as an extreme form of inhibition of cellular growth.

It has been recognized that locally produced Ang II is the central effector in several of the pathogenic mechanisms involved in cardiac hypertrophy, vascular remodeling, neointima formation, progressive glomerulosclerosis and tubulointerstitial fibrosis. Profibrogenic and hypertrophic actions of Ang II may play a centrale role during these processes. On the contrary, the antiproliferative and apoptotic properties 
of Ang II are much less characterized. It is still uncertain whether these effects of the hormone have pathophysiological relevance in vivo. The novel finding that Ang II is able to induce apoptosis is of great scientific interest, as apoptosis has been implicated in a wide variety of cardiovascular and renal diseases [reviewed in 10, 11]. The importance of this phenomenon for organ function in humans remains to be elucidated. However, increasing amount of evidence supports the notion that regulation of cell death by apoptosis may be an important determinant of organ function and lesion formation in many pathophysiological conditions of cardiovascular and renal systems. It is intriguing to speculate that the apoptotic influence exerted by Ang II may lead to the deletion of certain, functionally active cell populations in the heart, vessel wall or kidneys to exert specific morphological and functional alterations in these organs. In this article, we focus on the antiproliferative and apoptotic effects of Ang II and their possible pathophysiological consequences in cardiovascular and renal diseases.

Antiproliferative actions of Ang II via $\mathrm{AT}_{2}$ receptor

The biological function of the $\mathrm{AT}_{2}$ receptor remains poorly understood. Recently, several lines of evidence suggest that Ang II mediates inhibition of cell proliferation by acting through the $\mathrm{AT}_{2}$ receptor. In fibroblasts stably expressing the $\mathrm{AT}_{2}$ receptor, Ang II completely abolishes serum- or growth factor-induced cell proliferation [12, 13]. Vascular smooth muscle cells are believed to express predominantly, if not exclusively, the $\mathrm{AT}_{1}$ receptor that induces vasoconstriction and proliferation. In contrast, $\mathrm{AT}_{2}$ receptor overexpression in these cells reduces the proliferative response to Ang II [14]. Utilizing rat coronary endothelial cells expressing both $\mathrm{AT}_{1}$ and $\mathrm{AT}_{2}$ receptors, Stoll et al. demonstrated that Ang II significantly attenuated proliferation of endothelial cells when growth was stimulated either by fetal calf serum or basic fibroblast growth factor, and that this effect was mediated by the $\mathrm{AT}_{2}$ receptor $[15,16]$. Furthermore, they suggested that the relative proportion of $\mathrm{AT}_{1}$ and $\mathrm{AT}_{2}$ receptor subtypes on a given cell type would determine whether the peptide exerted proliferative or antiproliferative actions. Accordingly, in the presence of the $\mathrm{AT}_{2}$ receptor antagonist PD123319, mitogenic responses to Ang II have been demonstrated in quiescent endothelial and vascular smooth muscle cells, effects that were reversed by additional pretreatment with an $\mathrm{AT}_{1}$ receptor antagonist [16]. $\mathrm{AT}_{2}$ receptor stimulation inhibits $\mathrm{AT}_{1}$ receptor-mediated DNA synthesis and cell growth in myocytes and fibroblasts isolated both from neonatal rat hearts [17]. Similarly, inhibition of DNA synthesis by $\mathrm{AT}_{2}$ receptors was reported in zona glomerulosa cells from rat adrenal glands [18]. In rat pheochromocytoma cells (PC12W) stimulation of $\mathrm{AT}_{2}$ receptors not only inhibits growth factor-induced cell proliferation, but promotes neurite formation and enhances nerve growth factor-mediated neuronal differentiation 
[19]. The concept that the $\mathrm{AT}_{2}$ receptor function as an "antigrowth" receptor was also supported by the finding that $\mathrm{AT}_{2}$ receptor antagonists (PD123177 or CGP42112) augmented Ang II- or endothelin-1-induced hypertrophy of cultured rat cardiac myocytes [20].

Extrapolation of these results to in vivo circumstances seems to be more complex, therefore it is still uncertain whether $\mathrm{AT}_{2}$ receptors exert similar antiproliferative and/or growth-inhibitory effects in vivo. It is now well established that autocrine-paracrine vasoactive substances such as Ang II have the capacity to induce long-term changes in vessel structure, in addition to acute effects on vessel tone, and are important determinants of vascular lesion formation both in animal models and in humans. In the early ' 90 s Janiak et al. reported the $\mathrm{AT}_{2}$ receptor might be involved in the regulation of cellular proliferation during the neointima formation after ballooninjury of rat carotid artery [21]. In the same model, Nakajima et al. later reported that overexpression of the $\mathrm{AT}_{2}$ receptor (by in vivo gene transfer) significantly attenuates neointima formation [14]. In other experiments, they suggested a direct biological activity of $\mathrm{AT}_{2}$ receptors in the physiological decrease of DNA synthesis in fetal aortic smooth muscle cells at the latter stages of gestation in vivo [14].

Recently, Levy et al. and Sabri et al. have challenged the concept that the $\mathrm{AT}_{2}$ receptor mediates antiproliferative responses in vasculature [22, 23]. They reported that chronic administration of the $\mathrm{AT}_{2}$ receptor antagonist PD123319 had no influence on either systemic hemodynamic parameters or the cardiac hypertrophy in the rat model of Ang II-induced hypertension. PD123319 did antagonize the effect of Ang II on aortic smooth muscle cell growth and ECM protein expression in the vascular wall. In contrast, chronic blockade of $\mathrm{AT}_{1}$ receptors (losartan) resulted in normal arterial blood pressure and attenuated ventricular hypertrophy, but did not affect hypertensioninduced aortic hypertrophy and vascular collagen deposition. Based on these findings, they concluded that the vasotrophic effect of Ang II in vivo is at least partially mediated by $\mathrm{AT}_{2}$ receptors. More recently, however, $\mathrm{Li}$ et al. could not reproduce these results, showing little evidence of a role of $\mathrm{AT}_{2}$ receptors in the regulation of growth of smooth muscle cells in arteries obtained from different sites of rat vasculature [24].

Dramatic changes in the level of expression of both angiotensin receptor subtypes can be observed during ontogenesis. In adult kidneys, the predominant angiotensin receptor is $\mathrm{AT}_{1}$, and majority of studies found only a very small population of $\mathrm{AT}_{2}$ receptors in this organ in adults. However, situation is just the opposite during renal morphogenesis. $\mathrm{AT}_{2}$ receptors are abundantly and widely expressed in the developing fetus, particularly in mesenchymal tissues including the kidneys [25, 26]. The expression of $\mathrm{AT}_{2}$ receptors declines dramatically during the first days postpartum and, in the adults, $\mathrm{AT}_{2}$ expression is restricted to the adrenals, uterus, ovary, heart, kidneys and some specialized nuclei in the brain [25, 27]. Based on these findings, 
earlier reports postulated a definitive role of this receptor subtype in the control of cellular growth and differentiation during ontogenesis. This notion has been confirmed by studying the phenotype of $\mathrm{AT}_{2}$ receptor knock-out mice. $\mathrm{AT}_{2}$ receptor knock-out mice display a spectrum of congenital anomalies of the kidney and urinary tract (CAKUT) [28]. Diverse anatomic patterns of these CAKUT appear to share a common ontogenic mechanism of delayed apoptosis of undifferentiated mesenchymal cells in the nephrogenic tissues. The CAKUT seen in the $\mathrm{AT}_{2}$ receptor knock-out mice are very similar to the anomalies sometimes observed in humans. The role of $\mathrm{AT}_{2}$ receptors in renal development has been further confirmed by preliminary genetic studies that have identified a significant correlation between human CAKUT and a nucleotide transition in the human $\mathrm{AT}_{2}$ receptor coding gene [29].

Taken together, in vitro observations suggest a functional antagonism between $\mathrm{AT}_{1}$ and $\mathrm{AT}_{2}$ receptors in terms of cellular growth and proliferation. Studies utilizing mouse embryos with $\mathrm{AT}_{2}$ receptor gene null mutation strongly suggest that embryonic activation of this receptor subtype plays a significant role in normal growth and development of the kidney and ureter. Conversely, in vivo studies in adults have produced controversial results. One possible explanation for the discrepancy between in vitro and in vivo observations is that $\mathrm{AT}_{2}$ receptors may regulate cellular proliferation and apoptosis during embryonic development, but have minor importance in adult life. In many in vitro experiment, concomitant incubation with a growth factor is necessary to demonstrate the growth-inhibitory properties of $\mathrm{AT}_{2}$ receptors, which does not necessarily resemble in vivo situations. An additional limitation of in vitro studies is the possibility that receptor expression might be altered under these conditions. For example, $\mathrm{AT}_{2}$ receptor expression in mesangial cells markedly increased after cells reached confluency [30]. In addition, cultured mesangial cells from spontaneously hypertensive rats (SHR) showed much lower expression of the $\mathrm{AT}_{2}$ receptor and higher proliferative activity than those of normotensive Wistar-Kyoto rats, indicating that pathologic situations may influence $\mathrm{AT}_{2}$ receptor expression to result in enhanced mesangial cell proliferation and (probably) in renal damage [30].

Ang II and apoptosis: in vitro experiments

The concept of apoptosis due to activation of an energy-consuming endogenous cell suicide mechanism has been recently developed. Apoptosis is a physiological process by which unwanted or useless cells are eliminated during embryonic development, normal cell turnover, hormone-dependent tissue atrophy or in almost every functional aspect of the immune system [reviewed in 31-33]. Cells undergoing apoptosis show characteristic morphological and biochemical features such as cell shrinkage, membrane blabbing, formation of membrane bound vesicles (apoptotic 
bodies), chromatin condensation, DNA fragmentation, activation of intracellular cysteine protease cascade (caspases) and alterations in membrane asymmetry. Finally, apoptotic bodies are rapidly recognized and phagocytosed by either macrophages or adjacent epithelial cells without eliciting any inflammatory response. Fundamental differences exist between apoptosis and necrosis. The pathological process of necrosis is characterized by swelling of cells and intracellular organelles, as well as loss of membrane integrity and ultimate total cell lysis. In addition, necrotic cell death is often associated with extensive tissue damage that provokes an intensive inflammatory response.

Recent studies have provided convincing evidence that Ang II is capable of inducing apoptosis in various cell types through the activation of both $\mathrm{AT}_{1}$ and $\mathrm{AT}_{2}$ receptor subtypes (Table I). The proapoptotic properties of the $\mathrm{AT}_{2}$ receptor were reported for the first time in $\mathrm{PC} 12 \mathrm{~W}$ and fibroblast (R3T3) cell lines that express abundant $\mathrm{AT}_{2}$, but not $\mathrm{AT}_{1}$, receptors [34]. Prolonged serum depletion elicited apoptosis of R3T3 cells that was enhanced by Ang II treatment. Similarly, stimulation of $\mathrm{AT}_{2}$ receptors increased the number of $\mathrm{PC} 12 \mathrm{~W}$ cells undergo apoptosis upon depletion of nerve growth factor by a mechanism involving activation of protein tyrosine phosphatases (PTPases) including MAP kinase phosphatase-1 (MKP-1) [34, 35]. Horiuchi et al. reported that extracellular signal regulated kinase (ERK) plays a critical role in inhibiting apoptosis in PC12W cells by phopshorylating survival factor bcl-2. Furthermore, and the $\mathrm{AT}_{2}$ receptor inhibits ERK activation by MKP-1, resulting in inactivation of bcl-2. Furthermore induction of the apoptotic process [35]. Similar results have been obtained in N1E-115 neuroblastoma cells, where stimulation of the $\mathrm{AT}_{2}$ receptor inhibited activity of MAP kinases induced either by serum or by epidermal growth factor and induced apoptotic cell death [36]. In vascular smooth muscle cells stably transfected with $\mathrm{AT}_{2}$ receptor, selective stimulation of $\mathrm{AT}_{2}$ receptors enhanced serum-deprivation-induced apoptosis while $\mathrm{AT}_{1}$ receptor stimulation inhibited this process [37]. Consistent with these results, Hayashida et al. demonstrated that $\mathrm{AT}_{1}$ and $\mathrm{AT}_{2}$ receptors exert similar antagonistic effects on apoptosis in cultured rat ventricular myocytes expressing both receptor subtypes [38]. In these two studies, $\mathrm{AT}_{2}$ receptor-mediated apoptosis was associated with inactivation of ERK and c-Jun N-terminal Kinase (JNK) due to the dephosphorylation on tyrosine residues. Studies on mouse embryo fibroblasts have documented that cells from the wild-type animals, but not from the $\mathrm{AT}_{2}$ receptor knock-out animals, undergo apoptosis in response to Ang II treatment [39]. Finally, $\mathrm{AT}_{2}$ receptors have been associated with apoptotic changes in rat ovarian granulosa cells indicating that this receptor subtype might modulate the initiation and/or progression of follicle atresia involving apoptosis [40]. 
Table I

Apoptosis is mediated either by $A T_{1}$ or $A T_{2}$ receptors in various cell types

\begin{tabular}{lccc}
\hline Cell type & $\mathrm{AT}_{1}$ receptor & $\mathrm{AT}_{2}$ receptor & References \\
\hline Vascular smooth muscle cells & & + & 37 \\
Neonatal ventricular myocytes & & + & 38 \\
Ovarian granulosa cells & + & 40 \\
Embryonic fibroblasts & + & 39 \\
Pheochromocytoma cell line (PC12W) & & + & 34,35 \\
Fibroblast cell line (R3T3) & + & & 34 \\
Neonatal ventricular myocytes & + & & 40 \\
Adult ventricular myocytes & + & + & $42,50,51$ \\
Umbilical venous endothelial cells & + & & 44 \\
Coronary artery endothelial cells & & & 43 \\
\hline
\end{tabular}

Further complexity is added to the system if we consider that the $\mathrm{AT}_{1}$ receptor has also been implicated in the process of apoptotic cell death (Table I). The $\mathrm{AT}_{1}$ receptor can induce apoptosis both in neonatal and in adult cardiac myocytes by a mechanism involving PKC-mediated increase in cytosolic calcium concentration and stimulation of calcium-dependent endonuclease, identified as DNase I [41, 42]. Similarly, $\mathrm{AT}_{1}$ receptor activation has been linked to apoptotic changes in human coronary artery endothelial cells [43]. In addition, Dimmeler et al. demonstrated that Ang II induced apoptosis of human umbilical venous endothelial cells was associated with the activation of caspase- 3 , a central downstream effector of the caspase cascade [44]. Apoptosis was prevented by simultaneous blockade of both $\mathrm{AT}_{1}$ and $\mathrm{AT}_{2}$ receptors whereas surprisingly each individual receptor blocker alone was ineffective.

Recently, it has been suggested that autocrine-paracrine vasoactive substances such as NO and Ang II may act in opposition to achieve a balance between cell growth and cell survival during vascular remodeling. Consistent with this notion, Ang II directly antagonized NO-induced apoptosis of vascular smooth muscle cells through activation of the $\mathrm{AT}_{1}$ receptor subtype indicating the existence of countervailing influences of these molecules exist on the regulation of vascular apoptosis [45].

It is well established that the tumor supressor protein p53 regulates genomic stability, can produce cell cycle arrest and facilitates apoptosis [reviewed in 46]. It has been shown that introduction of wild-type p53 into cell lines that have lost endogenous p53 function causes growth arrest and induces apoptosis [47]. On the other hand, overexpression of wild-type p53 can trigger apoptosis in a wide range of cultured cell systems $[48,49]$. Recent observation indicates that overexpression of p53 in cardiac myocytes (induced by a replication-deficient adenoviral vector) upregulates the synthesis, release and local effects of Ang II on the $\mathrm{AT}_{1}$ surface receptor [50]. 
Downstream signaling events result in the activation of the endogenous cell death pathway leading finally to apoptosis of cardiac myocytes. Activation of the apoptotic pathway was associated with an increase in the bax/bcl-2 protein ratio. In another set of experiments, mechanical stretch-induced activation of $\mathrm{p} 53$ in myocytes was accompanied by enhancement of local RAS and increased susceptibility of myocytes to apoptosis [51]. The $\mathrm{AT}_{1}$ receptor blocker losartan completely abolished apoptotic responses in stretched myocytes, raising the possibility that the $\mathrm{AT}_{1}$ effector pathway may be critical in regulation of $\mathrm{p} 53$ function and cardiac cell death.

\section{Proapoptotic and antiproliferative signaling events via $A T_{2}$ receptor}

Recently, many similarities have been recognized between $\mathrm{AT}_{1}$ receptormediated signal transduction pathways and classic growth factor- or cytokinestimulated signaling events (Fig. 1). On the contrary, signaling pathways coupled to the $\mathrm{AT}_{2}$ receptor are still largely unknown. There is increasing evidence that the $\mathrm{AT}_{2}$ receptor reduces ERK activity by activation of PTPases such as MKP-1, which seems to be closely related to the antiproliferative and proapoptotic properties of this receptor subtype $[13,14,52,53]$. Very recently the third cytosolic loop domain of $\mathrm{AT}_{2}$ receptor was shown to activate PTPases that inhibits ERK via $G_{i}$-protein coupled mechanism [54]. However, the molecular mechanisms leading to the activation of PTPases have not been elucidated so far.

ERK cascade activation has been demonstrated by a number of studies [55-58] not only to be a key event in the signaling cascades employed by the $\mathrm{AT}_{1}$ receptor, but also responsible for the hypertrophic and proliferative responses of Ang II [59]. Suppression of ERK activity via the $\mathrm{AT}_{2}$ receptor suggests that opposing regulation of certain MAP kinases via different receptors for the same ligand exists. However, beside ERK cascade activation, the Jak/STAT pathway may also contribute to the hypertrophic and proliferative effects of Ang II [60, 61].

Two other MAP kinases (such as JNK and p38 kinase) have been generally proposed to be critical for antiproliferative and apoptotic responses induced by various stimuli [62]. However, there is no evidence to date whether JNK or p38 kinase activity is modulated upon $\mathrm{AT}_{2}$ receptor stimulation. Interestingly, $\mathrm{AT}_{1}$ receptor also activates these kinases in different cell types [63, 64].

The growth-promoting and profibrogenic effects of Ang II exerted via the $\mathrm{AT}_{1}$ receptor are closely associated with an increase in transitional activity of immediateearly response genes such as c-fos, c-jun and c-myc [65-68]. Proteins encoded by these genes act as transcription factors for various target genes that are involved in the development of cellular hypertrophy, mitogenesis, ECM protein metabolism and even in apoptosis. One may speculate that the antiproliferative effects of $\mathrm{AT}_{2}$ receptor are 
linked to repression of immediate-early gene expression, as shown for other antiproliferative agents. However, repression of immediate-early gene expression including c-fos or c-jun could not be detected as a part of the $\mathrm{AT}_{2}$ receptor coupled signaling process either in rat phaerochromocytoma cells [69] or in CHO cells (unpublished observation from our laboratory).

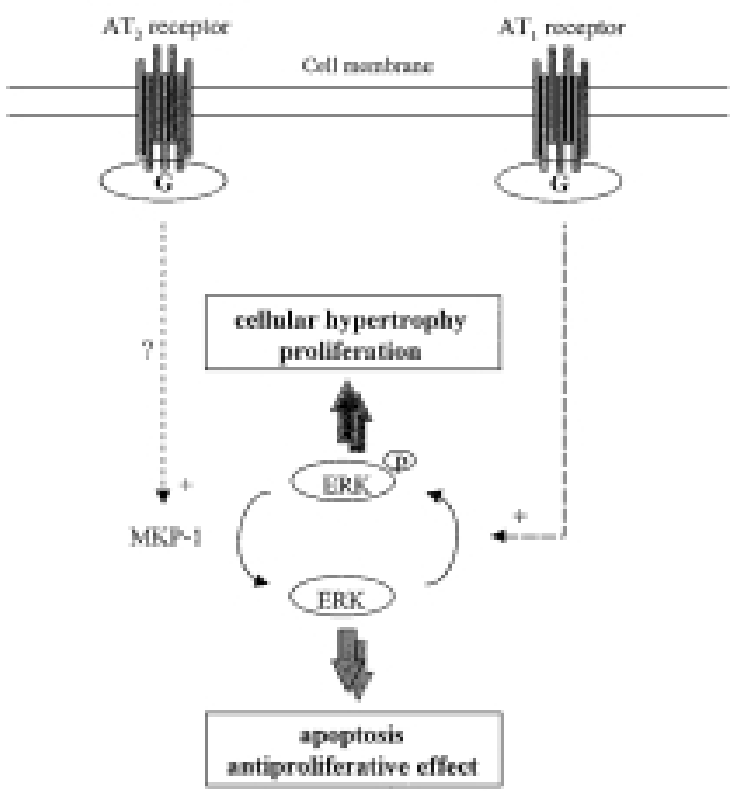

Fig. 1. A schematic model for signal transduction of $\mathrm{AT}_{1}$ and $\mathrm{AT}_{2}$ receptor mediated pro- and antiproliferative and apoptotic effects of Ang II

Does Ang II regulate apoptosis in vivo?

Apoptosis has been extensively studied for its involvement in immune responses, regulation of tumor cell growth and neurodegenerative disorders. In the last few years, an increasing number of studies have directed attention to its role in cardiovascular disease. It has been demonstrated that cardiac myocyte apoptosis occurs in patients undergoing cardiac transplantation for end-stage heart failure [72, 74]. This finding was interpreted as a contributing factor in the progressive loss of myocytes and in the evolution of the disease to terminal failure. Apoptotic changes have been shown experimentally in cardiomyocytes in response to a variety of insults which include mechanical stretch [51], pressure overload [71] or ischemia/reperfusion injury [76]. 
Similarly, increased apoptosis has been demonstrated recently in left ventricular hypertrophy [71] and in smooth muscle cells during vascular remodeling [75]. Hamet et al. revealed for the first time a higher level of apoptosis in the heart, kidneys and cultured cells from genetically hypertensive rats [70]. This finding suggests that the hypertensive state not only involves abnormal cell proliferation, but also an altered control of cell death by apoptosis.

At the present time, the pathophysiological meaning of increased cardiomyocyte apoptosis is obscure. Increased apoptosis might be a permissive phenomenon for subsequent development of a disease, as it has been suggested in cardiac hypertrophy $[70,75]$. Alternatively, failure of apoptosis might result in an imbalance between cell proliferation and apoptosis ultimately leading to a decrease in the number of functionally active cells. Hence, the progressive deterioration of left ventricular function in heart failure is likely to be mediated, in part, by ongoing loss of cardiomyocytes due to apoptosis. Finally, it is also conceivable that enhanced apoptosis is a secondary compensatory mechanism counteracting increased cellular proliferation and/or hypertrophy.

Although it is likely that at least a subset of the mediators of this process is conserved among cell types, mediators of cardiac cell apoptosis are largely unknown at present. Ang II might belong to the large family of regulatory molecules such as growth factors and cytokines that modulate cell survival and cell death by apoptosis. It is well established that hemodynamic overload activates the local RAS in the heart [77, 78]. Furthermore, the paracrine secretion of Ang II is involved in the hypertrophic response of cardiac myocytes to mechanical stretch [79]. Ang II might modulate cardiomyocyte cell death by apoptosis as well. Consistent with this notion, cardiomyocyte apoptosis was related to exaggerated local angiotensin-converting enzyme (ACE) activity in hypertrophic cardiac tissues of adult SHR [80].

Chronic administration of the ACE inhibitor, enalapril, has been reported to attenuate cardiomyocyte apoptosis in SHR and in dogs with chronic heart failure [73, 80]. Fortuno et al. demonstrated that SHR exhibited increased cardiac apoptosis that was associated with bax protein overexpression and with a decrease in the bcl-2/bax ratio, which were then normalized together with the rate of apoptotis after treatment with the $\mathrm{AT}_{1}$ receptor antagonist losartan [81].

In contrast to these studies, Sharifi et al. observed not decreased, but enhanced apoptosis of aortic smooth muscle cells in SHR after ACE inhibitor (enalapril) or calcium antagonist (amlodipine) treatment [82]. This phenomenon occurred in association with regression of vascular wall hypertrophy and hyperplasia in treated animals. Based on these findings, the authors concluded that the beneficial effects of these drugs on hypertensive vasculopathy are, at least in part, mediated by apoptosis. However, the mechanism for the enhanced apoptosis has been not elucidated. It is 
conceivable that it was a simple hemodynamic-dependent phenomenon. Alternatively, similar to growth factor withdrawal, depriving vascular smooth muscle cells of Ang II might have initiated apoptotic signals. Very recently, in the pulmonary system, captopril was reported to prevent apoptosis of human lung epithelial cells induced by agonistic anti-Fas receptor antibodies [83]. Later the same authors demonstrated the expression of both $\mathrm{AT}_{1}$ and $\mathrm{AT}_{2}$ receptors on the surface of these cells and they suggested a functional Ang II-dependent pathway for apoptosis of lung epithelial cells [84].

\section{Apoptosis in glomerulosclerosis}

Progressive glomerulosclerosis is characterized by a progressive loss of intact glomerular cells and their replacement by an amorphous, hyalinous and fibrous material leading finally to end-stage kidney disease. The pathogenetic process appears to be relatively independent of the initial insult. Progressive deletion of functionally active glomerular cells is one of the fundamental lesions of the disease. Whereas the mechanism of ECM accumulation has been studied extensively in recent years, the mechanism of cell loss during the development of glomerular scarring has been given minimal attention until now. Recent experimental findings indicate that apoptosis might be relevant in glomerular and/or tubular cell deletion during scar formation.

Harrison was the first to report light and electron microscopic evidence of renal cell apoptosis in proliferative types of human glomerulonephritis [85], proposing that apoptosis serves as a homeostatic mechanism allowing hypercellular glomeruli to return to normal. A few years later, Baker et al. confirmed this hypothesis by showing that apoptosis is the mechanism by which mesangial cells are cleaved from glomeruli during resolution of mesangial proliferative nephritis induced by Thy1.1 antibodies in rats [86].

An increased rate of apoptosis has been observed in sclerotic glomeruli in rats after subtotal (5/6) nephrectomy [87-89]. Thomas et al. concluded that apoptotic and proliferative changes take place simultaneously in the glomeruli and the tubulointerstitium, but after a time the former clearly exceeds the later leading to progressive scarring of the remnant kidney [88]. Apoptotic changes have been observed both in glomerular endothelial cells and in podocytes [89, 103]. Parallel increases in glomerular cell proliferation and apoptosis were reported in SHR after uninephrectomy [90]. Apoptosis was upregulated in human glomerulopathies including IgA nephropathy or lupus nephritis [87] and also in age-dependent glomerulosclerosis in rats [91]. Endothelin-1 transgenic mice are characterized by development of renal cysts and interstitial fibrosis leading to end-stage kidney disease [92]. Development of glomerulosclerosis was associated with an increased rate of apoptosis of glomerular, 
tubular and interstitial cells in transgenic animals [93]. Interstitial fibrosis due to cyclosporine A nephrotoxicity [94, 95] or chronic rejection of the transplanted kidney [96] has been also associated with an increase in apoptosis of tubular and interstitial cells. Furthermore, apoptosis has been implicated in the progressive renal atrophy that follows experimental ureteric obstruction [97].

Whether apoptotic phenomena plays a causal role in the pathogenesis and in the progression of diabetic nephropathy is not clear yet. Exposing proximal tubular cells in culture to high glucose was associated with increased rate of apoptosis [99, 100]. However, controversial results have been obtained in experimental diabetic nephropathy in vivo. Zhang et al. observed significant areas of apoptosis in diabetic rat kidney [98], whereas others failed to detect significant differences in the number of apoptotic cells between diabetic and normal murine kidney [102].

It has been widely accepted that cell-matrix interactions play a crucial role in the regulation of cellular growth, proliferation, differentiation and cytoskeletal structure. Recent findings indicate a potential role for interstitial matrix components in modulating cell death during fibrogenesis and scarring. Arg-Gly-Asp (RGD) sequencecontaining peptides, present in fibronectin and vitronectin, respectively, have been demonstrated to stimulate mesangial cell apoptosis possibly through the binding of integrins such as $\alpha 5 \beta 1$ and $\alpha \beta 3$ [98].

Based on the vast amount of data accumulated during the recent years, it is clear that Ang II exerts many hemodynamic and nonhemodynamic effects that contribute to renal injury and to the progression of renal parenchymal destruction. It is tempting to speculate that apoptotic cell loss induced by Ang II might occur during the course of progressive glomerulosclerosis, as well. $\mathrm{AT}_{2}$ receptor null mutant mice show enhanced collagen deposition, but less apoptotic cells in renal interstitium compared to the wildtype animals after ureteral obstruction [104]. This finding suggests that Ang II may influence apoptotic changes directly in glomeruli. In addition, very recently, transforming growth factor- $\beta$ (TGF- $\beta$ ) was suggested to modulate bcl-2/bax expression ratio and probably apoptosis in mesangial cells [105]. As Ang II stimulates the expression of TGF- $\beta$ in various cell types within the kidney $[106,107]$, this may represent an indirect pathway to impact on renal apoptotic processes. Furthermore, an increased rate of mesangial cell apoptosis has been also observed with the use of an in vitro model of glomerular hypertension [108]. Although this finding has not been confirmed in vivo, it is possible that Ang II-regulated hemodynamic changes during glomerular hypertension are associated with the initiation of an endogenous suicide mechanism in glomerular cells. 


\section{Conclusions}

Apoptosis is a tightly regulated form of cell death and is an essential counterpart of cellular growth and/or proliferation. An imbalance between cellular proliferation and apoptosis seems to represent an important determinant of tissue architecture and remodeling. Increased apoptosis may contribute to end-organ damage such as heart failure or development of progressive glomerulosclerosis. Ang II might be one of those many autocrine-paracrine substances that regulate these apoptotic changes in various cell types. Inhibition of the RAS with $\mathrm{ACE}$ inhibitors and $\mathrm{AT}_{1}$ receptor antagonists negatively influenced apoptosis in experimental studies that might be an additional factor to the wide range of the beneficial effects of these drugs.

Currently, very little is known concerning the duration of any apoptotic process in vivo and therefore, the relative importance of this phenomenon is still a matter of debate. Similarly, further studies are necessary to define the effect of modulating apoptosis directly on the development on these diseases. In the near future, molecular insight into renal apoptotic pathways will help to better understand the progressive nature of chronic cardiovascular and renal diseases and may provide a new basis for therapeutic strategies.

\section{Acknowledgements}

This work was supported by the Hungarian Kidney Foundation and by the intergovernmental cooperation project between the BMBF/DLR (UNG/056/96) in Germany, and the OMFB/TÉT D-39/99, FKFP 316/2000, AKP 98-109 3,2, OTKA 029260 in Hungary. Balázs Antus is a recipient of a scholarship from the German Academic Exchange Service (DAAD). István Mucsi is the recipient of the Bólyai scholarship of the Hungarian Academy of Sciences.

\section{REFERENCES}

1. Navar, L. G., Rosivall, L.: Contribution of the renal-angiotensin system to the control of intrarenal haemodynamics. Kidney Int. 25, 857-868 (1984)

2. Rosivall, L.: Intrarenal renin-angiotensin systems and its contribution to the regulation of glomerular haemodynamics. Nephrol. Dial. Transplant. 10, 1565-1568 (1995).

3. Wolf, D., Neilson, E. G.: Angiotensin II as a renal growth factor. J. Am. Soc. Nephrol. 3(9), 1531-1540 (1993).

4. Dostal, D. E., Hunt, R. A., Kule, C. E., Bhat, G. J., Karoor, V., McWhinney, C. D., Baker, K. M.: Molecular mechanism of angiotensin II in modulating cardiac function: intracardial effects and signal transaction pathway. J. Moll. Cell. Cardiol. 29, 2893-2902 (1997).

5. Homcy, C. J.: Signaling hypertrophy. How many switches, how many wires. Circulation 97, 1890-1892 (1998). 
6. Murphy, T. J., Alexander, R. W., Griendling, K. K., Runge, M. S., Bernstein, K. E.: Isolation of cDNA encoding the vascular type-1 angiotensin II receptor. Nature 355, 233-236 (1991).

7. Mukoyama, M., Nakajima, M., Horiuchi, M., Sasamura, H., Pratt, R. E., Dzau, V. J.: Molecular cloning of a novel angiotensin II receptor reveals a unique class of seven transmembrane receptor. J. Biol. Chem. 268, 24539-24542 (1993).

8. Sasaki, K., Yamamo, Y., Bardhan, S., Iwai, N., Murray, J. J., Hasegawa, N., Matsuda, Y., Inagami, T.: Cloning and expression of a complementary DNA encoding a bovine adrenal angiotensin II type-1 receptor gene from bovine adrenocortical cells. Nature 351, 230-232 (1991).

9. Kambayashi, Y., Bardhan, S., Takahasni, K., Tsuzuki, S., Inui, H., Hamakubo, T., Inagami, T.: Molecular cloning of a novel angiotensin II receptor isoform involved in phosphotyrosine phosphatase inhibition. J. Biol. Chem. 25 268, 24543-24546 (1993).

10. Mene, P., Amore, A.: Apoptosis: potential role in renal diseases. Nephrol. Dial. Transplant. 13, 1936-1943 (1998).

11. MacLellan W. B., Schneider M. D.: Death by design. Programmed cell death in cardiovascular biology and disease. Circ. Res. 81, 137-144 (1997).

12. Ozawa, Y., Suzuki, Y., Murakami, K., Miyazaki, H.: The angiotensin II type 2 receptor primarily inhibits cell growth via pertussis toxin-sensitive G proteins. Biochem. Biophys. Res. Commun. 228, 328-333 (1996).

13. Tsuzuki, S., Eguchi, S., Inagami, T.: Inhibition of cell proliferation and activation of protein tyrosine phosphatase mediated by angiotensin II type 2 (AT2) receptor in R3T3 cells. Biochem. Biophys. Res. Commun. 228, 825-830 (1996).

14. Nakajima, M., Hutchinson, H. G., Fujinaga, M., Hayashida, W., Morishita, R., Zhang, L., Horiuchi, M., Pratt, R. E., Dzau, V. J.: The angiotensin II type $2\left(\mathrm{AT}_{2}\right)$ receptor antagonizes the growth effects of the $\mathrm{AT}_{1}$ receptor: gain-of-function study using gene transfer. Proc. Natl. Acad. Sci. USA. 92, 10663-10667 (1995).

15. Metsärinne, K. P., Stoll, M., Gohlke, P., Paul, M., Unger T.: Angiotensin II is antiproliferative for coronary endothelial cells in vitro. Pharmaceut. Pharmacol. Lett. 2, 150-152 (1992).

16. Stoll, M., Steckelings, M., Paul, M., Bottari, S. P., Metzger, R., Unger, T.: The Angiotensin $\mathrm{AT}_{2}$ receptor mediates inhibition of cell proliferation in coronary endothelial cells. J. Clin. Invest. 95, 615-657 (1995).

17. Van Kesteren, C. A., Van Heugten, H. A., Lamers, J. M., Saxena, P. R., Schalekamp, H. A., Danser, A. H.: Angiotensin II-mediated growth and antigrowth effects in cultured neonatal rat cardiac myocytes and fibroblasts. J. Moll. Cell. Cardiol. 29, 2147-2157 (1997).

18. Mazzocchi, G., Malendowicz, L. K., Gottardo, G., Rebuffat, P., Nussdorfer, G. G.: Angiotensin II stimulated DNA synthesis in rat adrenal zona glomerulosa cells: receptor subtypes involved and possible signal transaction mechanism. Endocr Res. 23(3), 191-203 (1997).

19. Meffert, S., Stoll, M., Steckelings, U. M., Bottari, S. P., Unger, T.: The angiotensin II AT 2 receptor inhibits proliferation and promotes differentiation in PC12W cells. Mol. Cell. Endocrinol. 122, 59-67 (1996).

20. Booz, G. W., Baker, K. M.: Role of type 1 and type 2 angiotensin receptors in angiotensin II-induced cardiomyocyte hypertrophy. Hypertension 28, 635-640 (1996).

21. Janiak, P., Pillon, A., Prost, J. F., Vilaine, J. P.: Role of angiotensin subtype 2 receptor in neointima formation after vascular injury. Hypertension 20, 737-745 (1992).

22. Levy, B. I., Benessiano, J., Henrion, D., Caputo, L., Heymes, C., Duriez, M., Poitevin, P., Samule, J. $\mathrm{L}$.: Chronic blockade of $\mathrm{AT}_{2}$-subtype receptor prevents the effect of angiotensin II on the rat vascular structure. J. Clin. Invest. 98, 418-425 (1996) 
23. Sabri, A., Levy, B. I., Poitevin, P., Caputo, L., Faggin, E., Marotte, F., Rappaport, L., Samuel, J. L.: Differential roles of $\mathrm{AT}_{1}$ and $\mathrm{AT}_{2}$ receptor subtypes in vascular trophic and phenotypic changes in response to stimulation with angiotensin II. Arterioscle. Tromb. Vasc. Biol. 17, 257-264 (1997).

24. Li, J. S., Touyzn, R. M., Schiffrin, E. L.: Effects of $\mathrm{AT}_{1}$ and $\mathrm{AT}_{2}$ angiotensin receptor antagonists in angiotensin II-infused rats. Hypertension 31, 487-492 (1998).

25. Shanmugam, S., Lenkei, Zs. G., Gasc, J. M. R., Corvol, P. L., Llorens-Cortes, C. M.: Ontogeny of angiotensin II type $2\left(\mathrm{AT}_{2}\right)$ receptor mRNA in the rat. Kidney Int. 47, 1095-1100 (1995).

26. Ozono, R., Wang, Z., Moore, A. F., Inagami, T., Siragy, H. M., Carey, R. M.: Expression of subtype 2 angiotensin $\left(\mathrm{AT}_{2}\right)$ receptor protein in rat kidney. Hypertension 30, 1238-1246 (1997).

27. Grady, E. F., Sechi, L. A., Griffin, C. A., Schambelan, M., Kalinyak, J. E.: Expression of $\mathrm{AT}_{2}$ receptors in the developing rat fetus. J. Clin. Invest. 88, 921-933 (1991).

28. Nishimura, H., Yerkes, E., Hohenfellner, K., Miyazaki, Y., Ma, J., Hunley, T. E., Yoshida, H., Ichiki, T., Threadgill, D., Phillips, J. A., Hogan, B. M., Fogo, A., Brock, J. W., Inagami, T., Ichikawa, I.: Role of angiotensin type 2 receptor gene in congenital anomalies of the kidney and urinary tract, CAKUT, of mice and men. Mol. Cell. 3, 1-10 (1999).

29. Yerkes, E., Nishimura, H., Hohenfellner, K., Hunley, T., Yoshida, E., Kon, V., Phillips, J., Brock, J. W., Ischikawa, I.: Association between the angiotensin type II receptor $\left(\mathrm{AT}_{2}\right)$ genotype and congenital urinary tract anomalies (CUTA) in two independent cohorts. J. Am. Soc. Nephrol. 8, 397A (abstract) (1997).

30. Goto, M., Mukoyama, M., Suga, S., Matsumoto, T., Nakagawa, M., Ishibashi, R., Kasahara, M., Sugawara, A., Tanaka, I., Nakao, K.: Growth-dependent induction of Angiotensin II type 2 receptor in rat mesangial cells. Hypertension 30, 358-362 (1997).

31. Vermes, I., Haanen, C.: Apoptosis and programmed cell death in health and disease. Adv. Clin. Chem., 31, 177-246 (1999).

32. Cohen J. J.: Apoptosis. Immunol. Today 14, 126-130 (1993).

33. Stewart, B. W.: Mechanisms of apoptosis: Integration of genetic, biochemical, and cellular indicators. J. Natl. Canacer. Inst. 86, 1286-1296 (1994).

34. Yamada, T., Horiuchi, M., Dzau, V. J.: Angiotensin II type 2 receptor mediates programmed cell death. Proc. Natl. Acad. Sci. USA. 93, 156-160 (1996).

35. Horiuchi, M., Hayashida, W., Kambe, T., Yamada, T., Dzau, V. J.: Angiotensin type 2 receptor dephosphorylates bcl-2 by activating mitogen-activated protein kianse phsophatase- 1 and induces apoptosis. J. Biol. Chem. 272, 19022-19026 (1997).

36. Bedecs, K., Elbaz, N., Sutren, M., Masson, M., Susin, C., Strosberg, D., Nahmias, C.: Angiotensin II type 2 receptors mediate inhibition of mitogen-activated protein kinase cascade and functional activation of SHP-1 tyrosine phosphatase. Biochem. J. 325, 449-454 (1997).

37. Yamada, T., Akishita, M., Pollman, M. J., Gibbons, G. H., Dzau, V. J., Horiuchi, M.: Angiotensin II type 2 receptor mediates vascular smooth muscle cell apoptosis and antagonizes angiotensin II type 1 receptor action: an in vitro gene transfer study. Life Sci. 63, 289-295 (1998).

38. Hayashida, W., Horiuchi, M., Grandchamp, J., Dzau, V. J.: Antagonistic actions of Angiotensin II type-1 and type-2 receptors on apoptosis in cultured neonatal rat ventricular myocytes. Hypertension 28, 535 (abstract) (1996).

39. Li, W., Ye, Y., Fu, B., Wang, J., Yu, L., Ichiki, T., Inagami, T., Ichikawa, I., Chen, X.: Genetic deletion of $\mathrm{AT}_{2}$ receptor antagonizes Angiotensin II-induced apoptosis in fibroblasts of the mouse embryo. Biochem. Biophys. Res. Commun. 250, 72-76 (1998). 
40. Tanaka, M., Ohnishi, J., Ozawa, Y., Sugimoto, M., Usuki, S., Naruse, M., Murakami, K., Miyazaki, H.: Characterization of Angiotensin II receptor type 2 during differentiation and apoptosis of rat ovarian cultured granulosa cells. Biochem. Biophys. Res. Commun. 207, 593-598 (1995).

41. Cigola, E., Kajstura, J., Li, B., Meggs, L. G., Anversa, P.: Angiotensin II activates myocyte cell death in vitro. Exp. Cell. Res., 231, 363-371 (1997)

42. Kajstura, J., Cigola, E., Malhotra, A., Li, P., Cheng, W., Meggs, L. G., Anversa, P.: Angiotensin II induces apoptosis of adult ventricular myocytes in vitro. J. Moll. Cell. Cardiol. 29, 859-870 (1997).

43. Li, D., Yang, B., Philips, M. I., Metha, J. L.: Proapoptotic effects of Ang II in human coronary artery endothelial cells: role of AT1 receptor and PKC activation. Am. J. Physiol. 276, H786-H792 (1999).

44. Dimmeler, S., Rippmann, V., Weiland, U., Haendeler, J., Zeiher, A. M.: Angiotensin II induces apoptosis of human endothelial cells. Protective effect of nitric oxide. Circ. Res. 81, 970-976 (1997).

45. Pollmann, M. J., Yamada, T., Horiuchi, M., Gibbson, G. H.: Vasoactive substances regulate vascular smooth muscle cell apoptosis. Countervailing influences of nitric oxide and Angiotensin II. Circ. Res. 79, 748-756 (1996).

46. Lane, D. P.: p53, guardian of the genome. Nature 358, 15-16 (1992).

47. Mercer, W. E., Shields, M. T., Amin, M., Sauve, G. J., Appalla, E., Romano, J. W., Ullrich, S. J.: Negative growth regulation in a glioblastoma tumor cell line that conditionally express human wilde-type p53. Proc. Natl. Acad. Sci. USA. 87, 6166-6170 (1990).

48. Shaw, P., Bovey, R., Tardy, S., Sahli, R., Sordat, B., Costa, J.: Induction of apoptosis by wide-type p53 in human colon tumor-derived cell line. Proc. Natl. Acad. Sci. USA. 89, 4495-4499 (1992).

49. Yonish-Rouach, E., Resnitzky, D., Lotem, J., Sachs, L., Kimchi, A., Oren, M.: Wild-type p53 induces apoptosis of myeloid leukemic cells that is inhibited by interleukin-6. Nature 352, 345-347 (1991).

50. Pierzchalaski, P., Reiss, K., Cheng, W., Cirelli, C., Kajstura, J., Nitahara, J. A., Rizk, M., Capogrossi, M. C., Anversa, P.: p53 induces myocyte apoptosis via the activation of the renin-angiotensin system. Exp. Cell. Res. 234, 57-65 (1997).

51. Leri, A., Claudio, P. P., Li, Q., Wang, X., Reiss, K., Wang, S., Malhotra, A., Kajstura, J., Anversa, P.: Stretch-mediated release of Angiotensin II induces myocyte apoptosis by activating p53 that enhances the local renin-angiotensin system and decreases the bcl-2-tobax protein ration in the cell. J. Clin. Invest. 101, 1326-1342 (1998).

52. Fischer, T. A., Singh, K., O'Hara, D. S., Kaye, D. M., Kelly, R. A.: Role of $\mathrm{AT}_{1}$ and $\mathrm{AT}_{2}$ receptors in regulation of MAPKs and MKP-1 by ANG II in adult cardiac myocytes. Am. J. Physiol. 275, H906-H916 (1998)

53. Nahmias, C., Cazaubon, S. M., Briend-Sutren, M. M., Lazard, D., Villageois, P., Strosberg, A. D.: Angiotensin $\mathrm{II}_{\mathrm{AT}_{2}}$ receptors are functionally coupled to protein tyrosine dephosphorylation in N1E-115 neuroblastoma cells. Biochem. J. 306, 87-92 (1995).

54. Hayashida, W., Horiuchi, M., Dzau, V. J.: Intracellular third loop domain of Angiotensin II type-2 receptor. Role in mediating signal transaction and cellular function. J. Biol. Chem. 271, 21985-21992 (1996)

55. Zou, Y., Komuro, I., Yamazaki, T., Kudoh, S., Aikawa, R., Zhu, W., Shiojama, I., Hiroi, Y., Tobe, K., Kadowaki, T., Yazaki, Y.: Cell type-specific angiotensin II-evoked signal transaction pathways. Critical roles of $\mathrm{G}_{\beta \gamma}$ subunit, Src family, and Ras in cardiac fibroblasts. Circ. Res. 82, 337-345 (1998). 
56. Hamaguchi, A., Kim, S., Yano, M., Yamanaka, S., Iwao, H.: Activation of glomerular mitogenactivated protein kinases in angiotensin II-mediated hypertension. J. Am. Soc. Nephrol. 9, 372-380 (1998).

57. Ishida, M., Ishida, T., Thomas, S. M., Berk, B. C.: Activation of extracellular signal-regulated kinases (ERK1/2) by Angiotensin II is dependent on c-Src in vascular smooth muscle cells. Circ. Res. 82, 7-12 (1998).

58. Huszár, T., Mucsi, I., Antus, B., Terebessy, T., Masszi, A., Jeney, C., Hunyady, L., Mihalik, B., Goldberg, H. J., Thekkumkara, T. J., Rosivall, L.: Extracellular signal regulated kinase (ERK) and small GTP-binding protein $\mathrm{p} 21 \mathrm{Rac}-1$ are involved in the regulation of gene transcription by angiotensin II. Exp. Nephrol. (in press).

59. Kim, S., Izumi, Y., Yano, M., Hamaguchi, A., Miura, K., Yamanaka, S., Miyazaki, H., Iwao, H.: Angiotensin blockade inhibits activation of mitogen-activated protein kinases in rat balloon-injured artery. Circulation 97, 1731-1737 (1998).

60. Pan, J., Fukada, K., Kodama, H., Makino, S., Takahashi, T., Sano, M., Hori, S., Ogawa, S.: Role of angiotensin II in activation of the JAK/STAT pathway induced by acute pressure overload in the rat heart. Circ. Res. 81, 611-617 (1997).

61. Marrero, M. B., Schieffer, B., Li, B., Sun, J., Harp, J. B., Ling, B. N.: Role of Janus Kinase/Signal Transducer and Activator of Transcription and Mitogen-activated Protein Kinase cascades in Angiotensin II- and Platelet-derived Growth Factor-induced vascular smooth cell proliferation. J. Biol. Chem. 272, 24684-24690 (1997).

62. Force, T., Bonventre, J. V.: Growth factors and mitogen-activated protein kinase. Hypertension 31 , 152-161 (1998)

63. Kusuhara, M., Takahashi, E., Peterson, T. E., Abe, J., Ishida, M., Han, J., Ulevitch, R., Berk, B. C.: p38 Kinase is a negative regulator of angiotensin II signal transduction in vascular smooth muscle cells: effects on $\mathrm{Na}+/ \mathrm{H}+$ exchange and ERK1/2. Circ. Res. 19, 83:824-831 (1998).

64. Kudoh, S., Komuro, I., Mizuno, T., Yamazaki, T., Zou, Y., Shiojima, I., Takekoshi, N., Yazaki, Y.: Angiotensin II stimulates c-Jun NH2-terminal kinase in cultured cardiac myocytes of neonatal rats. Circ. Res. 80, 139-146 (1997).

65. Kawahara, Y., Sunako, M., Tsuda, T., Fukuzaki, H., Fukumoto, Y., Takai, Y.: Angiotensin induces expression of the c-fos gene through protein kinase $\mathrm{C}$ activation and calcium ion mobilization in cultured smooth muscle cells. Biochem. Biophys. Res. Commun. 150, 52-59 (1988).

66. Naftilan, A. J., Pratt, R. E., Eldridge, C. S., Dzau, V. J.: Angiotensin induces c-fos expression in smooth muscle cells via transcriptional control. Hypertension 13, 706-711 (1989).

67. Naftilan, A. J., Pratt, R. E., Dzau, V. J.: Induction of platelet-derived growth factor A-chain and c-myc gene expression by angiotensin II in cultured rat vascular smooth muscle cells. J. Clin. Invest. 83, 1419-1424 (1989).

68. Lyall, F., Doman, E. S., McQueen, J., Boswell, F., Kelly, M.: Angiotensin II increases proto-oncogene expression and phosphoinositide turnover in vascular smooth muscle cells via the angiotensin II $\mathrm{AT}_{1}$ receptor. J. Hypertens. 10, 1463-1469 (1992).

69. Steckelings, U. M., Bottari, S. P., Stoll, M., Wagner, J., Unger, T.: Repression of c-fos and c-jun gene expression is not part of $\mathrm{AT}_{2}$ receptor coupled signal transaction. J. Mol. Med. 76, 202-207 (1998).

70. Hamet, P., Richard, L., Dam, T. V., Teiger, E., Orlov, S. N., Gaboury, L., Gossard, F., Tremblay, J.: Apoptosis in target organs of hypertension. Hypertension 26, 642-648 (1995).

71. Teiger, E., Dam, T. V., Richard, L., Wisnewsky, C., Tea, B. S., Gaboury, L., Tremblay, J., Schwarz, K., Hamet, P.: Apoptosis in pressor overload-induced heart hypertrophy in the rat. J. Clin. Invest. 97, 2891-2897 (1996). 
72. Narula, J., Haider, N., Virmani, R., DiSalvo, T. G., Kolodgie, F. D., Hajjar, R. J., Schmidt, U., Semigran, M. J., Dec, W., Khaw, B.: Apoptosis in myocytes in end-stage heart failure. N. Eng. J. Med. 335, 1182-1189 (1996).

73. Goussev, A., Sharov, V. G., Shimoyama, H., Tanimura, M., Lesch, M., Goldstein, S., Sabbah, H. N.: Effects of ACE inhibition on cardiomyocyte apoptosis in dogs with heart failure. Am. J. Physiol. 275, H626-H631 (1998).

74. Olivetti, G., Abbi, R., Quaini, F., Kajstura, J., Cheng, W., Nitahara, J. A., Quiani, E., Loreto, C., Beltrami, C., Krajewski, S., Reed, J., Anversa, P.: Apoptosis in the failing human heart. N. Eng. J. Med. 336, 1131-1141 (1997).

75. Hamet, P., deBlois, D., Dam, T. V., Richard, L., Teiger, E., Tea, B. S., Orlov, S. N., Tremblay, J.: Apoptosis and vascular wall remodeling in hypertension. Can. J. Physiol. Pharmacol. 74, 850-861 (1996).

76. Gottlieb, R. A., Burleson, K. O., Kloner, R. A., Babior, B. M., Eiger, R. L.: Reperfusion injury induces apoptosis in rabbit cardiomyocytes. J. Clin. Invest. 94, 1621-1628 (1994).

77. Schunkert, H., Dzau, V. J., Tang, S. S., Hirsch, A. T., Apstein, C. S., Lorell, B. H.: Increased rat cardiac angiotensin converting enzyme activity and mRNA expression in pressure overload left ventricular hypertrophy: effects on coronary resistance, contractility and relaxation. J. Clin. Invest. 86, 1913-1920 (1990).

78. Baker, K. M., Chermin, M. I., Wixson, S. K., Aceto, J. F.: Renin-angiotensin system involvement in pressure-overload cardiac hypertrophy in rats. Am. J. Physiol. 259, H324-H332 (1990).

79. Sadoshima, J., Xu, Y., Slayter, H. S., Izumo, S.: Autocrine release of angiotensin II mediates stretch induced hypertrophy of cardiac myocytes in vitro. Cell 75, 977-984 (1993).

80. Diez, J., Panizo, A., Hernandez, M., Vega, F., Sola, I., Fortuno, M. A., Pardo, J.: Cardiomyocyte apoptosis and cardiac angiotensin-converting enzyme in spontaneously hypertensive rats. Hypertension 30, 1029-1034 (1997).

81. Fortuno, M. A., Ravassa, S., Etayo, J. C., Diez, J.: Overexpression of Bax protein and enhanced apoptosis in the left ventricle of spontaneously hypertensive rats: effects of $\mathrm{AT}_{1}$ blockade with losartan. Hypertension 32, 280-286 (1998).

82. Sharifi, A. M., Schiffrin, E. L.: Apoptosis in vasculature of spontaneously hypertensive rats. Effect of an angiotensin converting enzyme inhibitor and a calcium channel antagonist. Am. J. Hypertens. 11, $1108-1116(1998)$.

83. Uhal, B. D., Gidea, C., Bargout, R., Bifero, A., Ibarra-Sunga, O., Papp, M., Flynn, K., Filippatos, G.: Captopril inhibits apoptosis in human lung epithelial cells: a potential antfibrotic mechanism. Am. J. Physiol. 275, L1013-L1017 (1998).

84. Wang, R., Zagariya, A., Ibarra-Sunga, O., Gidea, C., Ang, E., Deshmukh, S., Chaudhary, G., Baraboutis, J., Filippatos, G., Uhal, B. D.: Angiotensin II induces apoptosis in human and rat alveolar epithelial cells. Am. J. Physiol. 276, L885-L889 (1999).

85. Harrison, D. J.: Cell death in diseased glomerulus. Histopathology 12, 679-683 (1988).

86. Baker, A. M., Mooney, A., Hughes, J., Lombardi, D., Johnson, R. J., Savill, J.: Mesangial cell apoptosis: the major mechanism for resolution glomerular hypercellularity in experimental mesangial proliferative nephritis. J. Clin. Invest. 94, 2105-2116 (1994).

87. Sugiyama, H., Kashihara, N., Makino, H., Yamasaki, Y., Ota, Z.: Apoptosis in glomerular sclerosis. Kidney Int. 49, 103-111 (1996).

88. Thomas, G. T., Yang, B., Wagner, B. E., Savill, J., El Nahas, A. M.: Cellular apoptosis and proliferation in experimental renal fibrosis. Nephrol. Dial. Transplant. 13, 2216-2226 (1998). 
89. Kitamura, H., Shimizu, A., Masuda, Y., Ishizaki, M., Sugisaki, Y., Yamanaka, N.: Apoptosis in glomerular endothelial cells during the development of glomerulosclerosis in the remnant-kidney model. Exp. Nephrol. 6, 328-336 (1998).

90. Rodriguez-Lopez, A. M., Flores, O., Arevalo, M. A., Lopez-Novoa, J. M.: Glomerular cell proliferation and apoptosis in uninephrectomized spontaneously hypertensive rats. Kidney Int. $\mathbf{5 4}$ (Suppl. 68), S36-40 (1998).

91. Thomas, S. E., Anderson, S., Gordon, K. L., Oyama, T. T., Shankland, S. J., Johnson, R. J.: Tubulointerstitial disease in aging: evidence for underlying peritubular capillary damage, a potential role for renal ischemia. J. Am. Soc. Nephrol. 9, 231-242 (1998).

92. Hocher, B., Thöne-Reineke, C., Rohmeiss, P., Endothelin-1 transgenic mice develop renal cysts, interstitial fibrosis and glomerulosclerosis but not hypertension. J. Clin. Invest. 99, 1380-1389 (1997).

93. Hocher, B., Rohmeiss, P., Thöne-Reineke, C., Schwarz, A., Burst, V., van der Woude, F., Bauer, C., Theuring, F.: Apoptosis in the kidney of endothelin-1 transgenic mice. J. Cardiovasc. Pharmacol. 31(Suppl. 1), S554-556 (1998).

94. Ito, H., Kasagi, N., Shoromi, K., Osaki, M., Adachi, H.: Apoptosis in human allograft kidneys. Analysis by terminal deoxynucleotidyl transferase-mediated dUTP-biotin nick end labeling. Transplantation 60, 794-798 (1995).

95. Thomas, S. E., Andoh, T. F., Pichler, R. H., Shankland, S. J., Couser, W. G., Bennett, W. M., Johnson, R. J.: Accelerated apoptosis characterizes cyclosporine-associated interstitial fibrosis. Kidney Int. 53, 897-908 (1998).

96. Laine, J., Etelämäki, P., Holmberg, C., Dunkel, L.: Apoptotic cell death in human chronic renal allograft rejection. Transplantation 63, 101-105 (1997).

97. Troung, L. D., Petrusevska, G., Yang, G., Gurpinar, T., Shapell, S., Lechango, J., Rouse, D., Suki, W. N.: Cell apoptosis and proliferation in experimental chronic obstructive uropathy. Kidney Int. 50, 200-207 (1996).

98. Chen, X., Wang, J., Fu, B., Yu, L.: RGD-containing peptides trigger apoptosis in glomerular mesangial cells of adult human kidneys. Biochem. Biophys. Res. Commun. 234, 594-595 (1997).

99. Ortiz, A., Ziyadeh, F. N., Neilson, E. G.: Expression of apoptosis-regulatory genes in renal proximal tubular epithelial cells exposed to high ambient glucose and in diabetic kidneys. J. Investig. Med. 45, 50-56 (1997)

100. Ishii, N., Ogawa, Z., Suzuki, K., Numakami, K., Saruta, T., Itoh, H.: Glucose loading induces DNA fragmentation in rat proximal tubular cells. Metabolism 45, 1348-1353 (1996).

101. Zhang, W., Khanna, P., Chan, L. L., Campbell, G., Ansari, N. H.: Diabetes-induced apoptosis in the rat. Biochem. Mol. Med. 61, 58-62 (1997).

102. Kuan, C. J., Al-Douahji, M., Shankland, S. J.: The Cyclin kinase inhibitor $\mathrm{p} 21^{\text {WAF1,CIP1 }}$ is increased in experimental diabetic nephropathy: potential role in glomerular hypertrophy. J. Am. Soc. Nephrol. 8, 986-993 (1998).

103. Shiiki, H., Sasaki, Y., Nishino, T., Kimura, T., Kurioka, H., Fujimoto, S., Dohi, K.: Cell proliferation and apoptosis of the glomerular epithelial cells in rats with puromycin amononucleoside nephrosis. Pathobiology 66, 221-229 (1998).

104. Ma, J., Nishimura, H., Fogo, A., Kon, V., Inagami, T., Ichikawa, I.: Accelerated fibrosis and collagen deposition develop in the renal interstitium of angiotensin type 2 receptor null mutant mice during ureteral obstruction. Kidney Int. 53, 937-944 (1998). 
105. Yoshimura, A., Uda, S., Inui, K., Nemoto, T., Sugenoya, S., Sharif, S., Yakota, N., Watanabe, S., Ideura, T.: Expression of bcl-2 and bax in glomerular disease. Nephrol. Dial. Transplant. 14 (Suppl 1), 55-57 (1999).

106. Ketteler, M., Border, W. A., Noble, N. A.: Cytokines and L-arginine in renal injury and repair. Am. J. Physiol. 267, 197-200 (1994).

107. Ketteler, M., Noble, N. A., Border, W. A.: Transforming growth factor-beta and angiotensin II: missing link from glomerular hyperfiltration to glomerulosclerosis? Ann. Rev. Physiol. 57, 279-295 (1995).

108. Singhal, P. C., Gibbons, N., Franki, N., Reddy, K., Sharma, P., Mattana, J., Wagner, J. D., Bansal, V.: Simulated glomerular hypertension promotes mesangial cell apoptosis and expression of cathepsin-B and SGP-2. J. Investing. Medicine 46, 42-50 (1998). 